\title{
Itch in Children with Type 1 Diabetes: A Cross- Sectional Study
}

\author{
Aleksandra A. Stefaniak - Agnieszka Zubkiewicz-Kucharska • \\ Łukasz Matusiak · Anna Noczyńska · Jacek C. Szepietowski (D)
}

Received: April 25, 2020 / Published online: June 8, 2020

(c) The Author(s) 2020

\begin{abstract}
Introduction: Type 1 diabetes (T1D) is reported to be one of the most common medical conditions in school-age youth and is ranked third in the prevalence of pediatric conditions. Only a few studies have investigated the occurrence of itch in diabetes mellitus, reporting conflicting data. The purpose of this study was to investigate the prevalence of itch in T1D to provide itch characteristics and to explore the potential underlying causes.
\end{abstract}

Methods: This prospective study evaluated itch among 100 children with T1D. Itch intensity was assessed with the Numerical Rating Scale (NRS) and the 4-Item Itch Questionnaire (4IIQ). The Children's Dermatology Life Quality Index (CDLQI) was implemented to assess the quality of life issues. Various clinical features and factors influencing itch were also examined. Skin

Digital Features To view digital features for this article go to https://doi.org/10.6084/m9.figshare.12357281.

A. A. Stefaniak · Ł. Matusiak · J. C. Szepietowski ( $₫)$ Department of Dermatology, Venereology and Allergology, Wroclaw Medical University, ul. Chałubińskiego 1, 50-368 Wrocław, Poland e-mail: jacek.szepietowski@umed.wroc.pl

A. Zubkiewicz-Kucharska · A. Noczyńska Department of Endocrinology and Diabetology for Children and Adolescents, Wroclaw Medical University, ul. Chałubińskiego 2a, 50-368 Wrocław, Poland dryness was evaluated clinically by non-invasive assessment of epidermis moisturizing.

Results: Itch occurred in $22 \%$ of children with T1D with the mean maximal intensity of $5.9 \pm 3.0$ points in NRS and $6.7 \pm 3.5$ points in 4IIQ (median, 5.5 points). In the majority of patients, the itch was limited to a few regions of the body; usually, the upper limbs $(68.2 \%)$ were affected, followed by the lower limbs (50\%) and the trunk (31.8\%). Clinically examined skin xerosis was significantly more advanced in children with itch compared with those without itch $(p<0.01)$. The mean CDLQI score in the itchy group was $4.0 \pm 4.7$ points (median, 2.5 points), indicating a small impairment of quality of life. The intensity of itch (both NRS last 3 days and NRS last $24 \mathrm{~h}$ ) correlated positively with life quality impairment $(R=0.7$; $p=0.015$ and $R=0.8, p=0.002$, respectively).

Conclusions: Our study found itch as a moderately frequent symptom in children with T1D; however, itch presence and intensity may relevantly debilitate quality of life among subjects. We suggest that dryness of the skin may play a role in the pathogenesis of itch in this population.

Keywords: Itch; Pruritus; Type 1 diabetes mellitus 


\section{Key Summary Points}

Type 1 diabetes (T1D) is reported to be one of the most common medical conditions in school-age youth, and it is ranked third in the prevalence of pediatric conditions.

However, only a few studies investigated the occurrence of itch in diabetes mellitus, reporting conflicting data. Studies on the child population with T1D are missing.

This study aimed to investigate the prevalence of itch in T1D to provide itch characteristics and to explore the potential underlying causes.

Itch is a moderately frequent symptom among children with T1D (22\%). Dryness of the skin may play a role in the pathogenesis of itch in this population.

Itch presence and intensity may relevantly impair quality of life among the affected subjects.

\section{INTRODUCTION}

Diabetes mellitus (DM) and its complications are a growing problem worldwide. The International Diabetes Federation estimated that 1 in 11 adults aged 20-79 years (which amounts to 415 million adults) had DM globally in 2015 [1]. Type 1 diabetes (T1D) is reported to be one of the most common medical conditions in school-age youth, and it is ranked third in the prevalence of pediatric conditions [2]. More than $90 \%$ of patients with T1D are diagnosed before the age of 30 [3]. Approximately 2-3 teenagers per 1000 are currently diagnosed with this type of diabetes, and this ratio is rising by $3 \%$ per annum in European children, with an increasing number being diagnosed in early childhood [4].

Itch is defined as an unpleasant sensation that leads to intensive scratching [5]. It is a frequent and distressing symptom occurring not only in dermatologic conditions but also in chronic systemic diseases $[5,6]$, posing a high burden and decrease in quality of life (QoL) of patients $[7,8]$. Most researchers classify itch in diabetes, according to the International Forum for the Study of Itch (IFSI), as systemic itch [9]; however, some authors suggested mixed etiology of diabetic itch with the additional involvement of both dermatologic and neurologic components [10-12]. Only a few studies investigated the occurrence of itch in DM, reporting a wide prevalence ranging from 18.4-27.5\% [13]. However, these studies used inconsistent definitions and various tools for itch evaluation and included heterogeneous diabetic populations. Studies on itch in T1D, employing currently accepted methodology, are scarce.

Therefore, we set up a prospective study among pediatric patients with T1D, using standardized methods for itch assessment to investigate the prevalence of itch, to provide itch characteristics and to explore the potential underlying causes.

\section{METHODS}

\section{Study Population and Design}

This prospective cross-sectional study was performed between April 2019 and December 2019. The project was approved by the local Ethical Committee (ST.C260.18.019). The study procedures were carried out in agreement with the Helsinki Declaration of 1964 and its later amendments, and good clinical practice guidelines. Written informed consent to participate was obtained from all children and their carers before enrollment, they were also informed of their right to leave the study at any time. We approached 104 consecutive patients aged 6-18 years who were treated in the Department of Endocrinology and Diabetology for Children and Adolescents. The mother of one child refused participation in the study because of the severe course of T1D (hospitalization due to diabetic ketoacidosis); the mother of another child refused participation in the study without specifying the reasons (response rate: 98\%). The inclusion criteria were diagnosis of T1D 
Table 1 Basic demographics of the subjects

\begin{tabular}{ll}
\hline Sex $(n)$ & 100 \\
Female & 57 \\
Male & 43 \\
Age (years), mean \pm SD & $13 \pm 3.1$ \\
Range & $(6-18)$ \\
Median & 13 \\
BMI $\left(\mathrm{kg} / \mathrm{m}^{2}\right)$, mean \pm SD & $20.6 \pm 3.9$ \\
Range & $(12.8-33.1)$ \\
Median & 20.7 \\
Duration of diabetes (years), mean \pm SD & $4.6 \pm 3.6$ \\
Range & $(0-13)$ \\
Median & 4 \\
\hline
\end{tabular}

$S D$ standard deviation, $B M I$ body mass index

according to internationally accepted criteria [14] and an informed written participation agreement signed by the parent. Exclusion criteria included: mental status changes making the patient unable to make a detailed assessment of itch; known severe renal or liver disease; a history of chronic dermatologic disease. Among 102 patients, 2 subjects suffered from dermatologic disorders (one patient had atopic dermatitis and one suffered from psoriasis). Therefore, the final study group constituted 100 pediatric patients with T1D (Table 1).

After inclusion, detailed information on demographics, clinical history, comorbidities and physical findings was recorded. The results of routine laboratory blood tests were also noted with particular emphasis on glycated hemoglobin (HbA1c) and fasting plasma glucose (FPG). If multiple laboratory tests were available, the results closest to the day of dermatologic examination would be chosen.

The main clinical parameter, the presence of chronic itch (CI), was documented, including the affected anatomical locations. A numerical rating scale (NRS; 0: no itch; 10 points: worst imaginable itch) was utilized to assess maximal values of itch intensity in both the last 3 days and last $24 \mathrm{~h}$. NRS cutoff points are as follows: $1-<3$ points represent mild itch, 3-7 points moderate itch, $\geq 7-9$ points severe itch and $\geq 9$ points very severe itch [15].

Additionally, the 4-Item Itch Questionnaire (4IIQ), previously used by our group in many studies on different types of itch [16-19], was employed to assess CI extensity, severity, frequency and associated sleep impairment. Furthermore, the description of cutaneous sensations associated with itch, the emotional burden of itch, sleep impairment, certain factors influencing itch intensity and itch impact on psyche were noted.

The Children's Dermatology Life Quality Index (CDLQI) [20-22] was applied to assess relationships of itch with life quality impairment.

Skin dryness was assessed clinically using a graduated 4-point scale (range $0-3$ points; 0 points - no symptoms of dry skin; 1 , ashiness, but no discernible flakes; 2 , small to medium flakes; 3, large flakes and a prominent "cracked glass pattern") [23, 24]. Subsequently, noninvasive corneometric assessment of epidermal hydration, using a Corneometer CM825 (Courage + Khazaka Electronic GmbH, Köln Germany) was carried out. All measurements were performed on four areas of the skinforearm, lower leg, abdomen and chest-at stable room temperature $\left(20-22^{\circ} \mathrm{C}\right)$ and air humidity (40-50\%) after a 10 -min rest in the lying position.

Neurologic examination of the patients was done according to the guidelines of the American Diabetes Association [25]. Each patient was questioned as to the presence or absence of pain (characteristic of neuropathic pain such as burning, stabbing or shock-like); numbness, tingling and weakness in the feet; the presence or absence of similar upper-limb symptoms; and the presence or absence of unsteadiness on ambulation. Five sensory testings were evaluated: pain sensation with a pinprick, temperature sensation with the Tip-therm (Thermo Feel $\left.{ }^{\circledR}\right)$ device, light touch sensation using the Semmes-Weinstein monofilament test with standardized $10 \mathrm{~g}$ monofilament, vibratory sensation with a $128-\mathrm{Hz}$ standard tuning fork and the position sensation. All tests were 
performed at the first toe and rated as normal or abnormal.

\section{Statistical Analysis}

All variables were assessed for normal or nonnormal distribution to apply corresponding statistical tests. Differences between groups were determined using the Mann-Whitney $U$ test with reference to the non-normal distribution of evaluated variables. Correlations were determined using Spearman's correlation analysis. The level of significance was set at $\alpha=0.05$. The resulting $p$ values were considered significant if $p<0.05$. Statistical analyses were performed using Statistica 12 software (StatSoft, Tulsa, OK, USA).

The sample size of the study cohort was determined by sample size calculation using the principle of the anticipated response distribution of $50 \%$, with a $95 \%$ confidence interval and $10 \%$ precision.

\section{RESULTS}

\section{General Demographics, Laboratory Glycemic Control, Systemic Comorbidities and Diabetic Neuropathy}

Among 100 studied patients, 22 subjects (22\%) reported itch during the course of T1D. The recruited number of subjects fulfilled the abovementioned sample size criterion, as 97 or more measurements/surveys were needed.

In 12 patients (12\%), itch was present during the last 3 days. Clinical characteristics of the examined individuals displayed in different itch statuses (itch during the course of diabetes vs. itch during last 3 days vs. no itch) are shown in Table 2. There was no significant difference between the analyzed groups concerning sex, age, body mass index (BMI), duration of T1D and basic laboratory examinations (Table 2). No correlations were documented between any assessment of itch intensity and values of HbA1c and FPG (NRS during the last 3 days: with HbA1c- $R=0.2 p=0.6$, with FPG- $R=-0.4$ $p=0.4$; NRS during the last $24 \mathrm{~h}$ : with HbA1C-
$R=0.5 p=0.1$, with FPG- $R=0.05 p=0.9$; 4IIQ: with $\mathrm{HbA} 1 \mathrm{C}-R=0.02 \quad p=0.9$ with FPG$R=-0.02 p=0.9$ ).

The most common systemic comorbidities encompassed thyroid disorders (11\%), celiac disease $(7 \%)$ and asthma (4\%) without significant differences between itchy and non-itchy patients (detailed data not shown). All patients (100\%) were euthyroid. Among the examined group, none of the subjects had signs of diabetic polyneuropathy in the basic neurologic examination.

\section{Itch Characteristics}

Twelve patients out of 22 itchy subjects (54.5\%) had itch present during the last 3 days. In this group of subjects, the maximal NRS score for itch intensity during the last 3 days was $5.9 \pm 3.0$ points, while during the last $24 \mathrm{~h}$ it was assessed as $5.0 \pm 3.8$ points, indicating moderate itch intensity. Mild itch was observed in $16.7 \%$ of patients, moderate itch in $41.7 \%$ of patients, and severe or very severe itch in $41.7 \%$ of patients. The mean 4IIQ score was $6.7 \pm 3.5$ points (median, 5.5 points).

Notably, in all 22 itchy subjects, $25 \%$ of patients reported that itching occurs constantly every day. More than $40 \%$ of itchy patients $(40.9 \%)$ reported a shorter duration of single itch episodes lasting < $1 \mathrm{~min}$; however, $13.6 \%$ of patients reported feeling itch all the time without breaks.

In the majority of patients, itch was limited to a few regions of the body; most commonly, the upper limbs $(68.2 \%)$ were affected, followed by the lower limbs (50\%) and the trunk (31.8\%). Not even a single subject reported generalized itch. Itch requiring scratching was found in $86.4 \%$ of itchy individuals.

Itch occurred most frequently during the evening and night $(27.3 \%)$, very rarely in the morning and midday. Usually, itch was not accompanied by other unpleasant cutaneous sensations $(81.8 \%)$. Less commonly, it was described as warming (13.6\%), stinging (9.1\%) or tingling (4.5\%). Patients frequently described that itch did not affect their mood (51.9\%); 
Table 2 Basic demographics and laboratory glycemic control for the subsequent groups of subjects

\begin{tabular}{|c|c|c|c|c|}
\hline & $\begin{array}{l}\text { Itch during the course of } \\
\text { diabetes }\end{array}$ & $\begin{array}{l}\text { Itch during the last } 3 \\
\text { days }\end{array}$ & No itch & $\begin{array}{l}p- \\
\text { value }^{*}\end{array}$ \\
\hline $\operatorname{Sex}(n)$ & 22 & 12 & 78 & NS \\
\hline Women & 12 & 6 & 35 & \\
\hline Men & 10 & 6 & 33 & \\
\hline Age (years), mean $\pm S D$ & $11.8 \pm 3.5$ & $12.6 \pm 3.6$ & $13.3 \pm 3.1$ & NS \\
\hline Range & $(7-17)$ & $(7-17)$ & $(6-18)$ & \\
\hline Median & 11 & 13 & 14 & \\
\hline BMI $\left(\mathrm{kg} / \mathrm{m}^{2}\right)$, mean $\pm \mathrm{SD}$ & $20.05 \pm 4.2$ & $21.1 \pm 4.7$ & $20.7 \pm 3.8$ & NS \\
\hline Range & $(12.8-26.9)$ & $(13.5-26.9)$ & $(14.5-33.1)$ & \\
\hline Median & 21.6 & 21.7 & 20.7 & \\
\hline $\begin{array}{l}\text { Duration of diabetes (years), } \\
\text { mean } \pm S D\end{array}$ & $5.4 \pm 2.7$ & $5.75 \pm 2.7$ & $4.4 \pm 3.8$ & NS \\
\hline Range & $(0-12)$ & $(2-12)$ & $(0-13)$ & \\
\hline Median & 5 & 5 & 3 & \\
\hline $\mathrm{HbAlC}(\%)$, mean $\pm \mathrm{SD}$ & $8.6 \pm 1.6$ & $8.8 \pm 1.6$ & $9.3 \pm 2.9$ & NS \\
\hline Range & $(6.5-12.9)$ & $(6.9-12.9)$ & $(5.6-19.3)$ & \\
\hline Median & 8.35 & 8.35 & 8.6 & \\
\hline $\mathrm{FPG}(\mathrm{mg} / \mathrm{dl})$, mean $\pm \mathrm{SD}$ & $168.6 \pm 72.2$ & $181.2 \pm 76.1$ & $160.8 \pm 63.8$ & NS \\
\hline Range & $(87-300)$ & $(91-300)$ & $(66-315)$ & \\
\hline Median & 153 & 167 & 147.5 & \\
\hline
\end{tabular}

For both comparisons, i.e., between the no itch group and itch during the last 3 days as well as between no itch and itch during the course of the disease

$S D$ standard deviation, $N S$ not significant, $B M I$ body mass index, $H b A 1 C$ glycated hemoglobin, FPG fasting plasma glucose

however, for some subjects itch was annoying $(27.3 \%)$ and burdensome (18.2\%).

Itch contributed to difficulties in falling asleep and sleep disturbances, described as "waking during the night sleep due to itching" in $18.2 \%$ of affected individuals, and one of them $(4.5 \%)$ reported the use of soporifics.

The most common exacerbating factors included heat (18.2\%) and hot water (13.6\%), while diabetic diet and cold water were considered alleviating factors in $22.7 \%$ and $13.6 \%$ of patients, respectively. Most of the patients (54.5\%) did not see any correlation between analyzed factors and itch; $31.8 \%$ of subjects regarded itch as a factor negatively influencing their mood with $27.3 \%$ finding it affected concentration, e.g., at school.

\section{Itch and Skin Xerosis}

Skin xerosis, examined clinically, was significantly more advanced in children with itch compared with those without itch $(p<0.01)$. The skin seemed to be even drier in patients with itch occurring during the last 3 days compared with all 22 subjects reporting itch during the course of T1D; however, the difference was 
Table 3 Dry skin and itch in children with diabetes

\begin{tabular}{|c|c|c|c|c|}
\hline & $\begin{array}{l}\text { Itch during the course of } \\
\text { diabetes }\end{array}$ & $\begin{array}{l}\text { Itch during last } \\
3 \text { days }\end{array}$ & No itch & $P$ value ${ }^{*}$ \\
\hline Skin xerosis (points), mean $\pm S D$ & $0.8 \pm 1.0$ & $1.25 \pm 0.6$ & $0.3 \pm 0.5$ & $<0.01$ \\
\hline median & 1 & 1 & 0 & \\
\hline \multicolumn{5}{|l|}{$\begin{array}{l}\text { Epidermal hydration (AU). } \\
\text { mean } \pm \text { SD (median) }\end{array}$} \\
\hline Forearm & $25.6 \pm 7.7(27.1)$ & $28.2 \pm 8.6(27.1)$ & $25.0 \pm 7.6(23.7)$ & NS \\
\hline Lower leg & $27.7 \pm 12.7(28.0)$ & $28.6 \pm 9.7(25.5)$ & $30.0 \pm 11.3(28.1)$ & NS \\
\hline Abdomen & $24.2 \pm 12.8(23.7)$ & $27.0 \pm 13.9(21.3)$ & $25.6 \pm 11.4(22.3)$ & NS \\
\hline Chest & $38.2 \pm 12.0(39.0)$ & $38.8 \pm 11.4(39.3)$ & $40.0 \pm 14.0(38.3)$ & NS \\
\hline
\end{tabular}

$S D$ standard deviation, $N S$ not significant

* For both comparisons, i.e., between the no itch group and itch during the last 3 days as well as between no itch and itch during the course of the disease

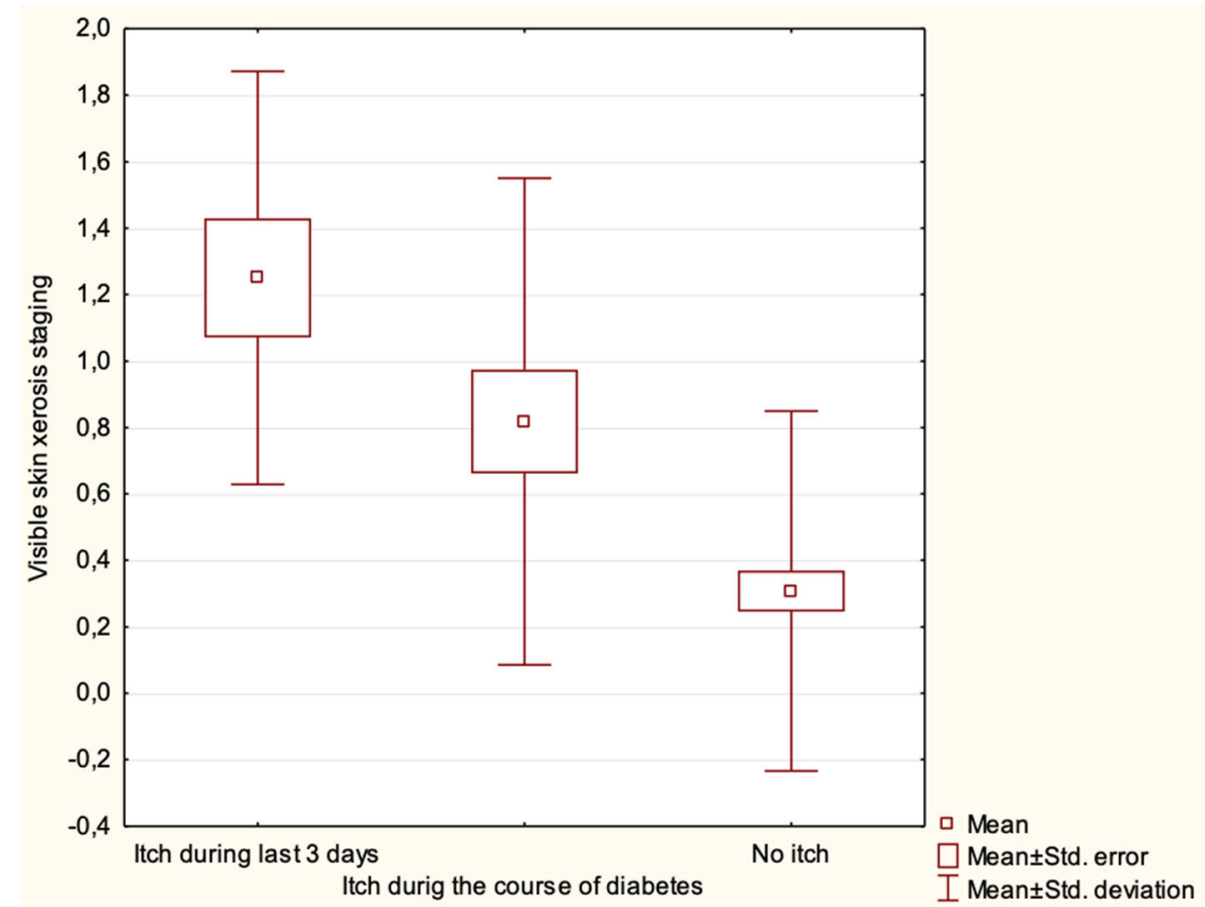

Fig. 1 Visible skin xerosis in children with itch during the last 3 days, during the course of the disease, compared with those without itch. Results are statistically significant

not statistically significant $(p>0.05)$ (Table 3 , Fig. 1).

Using corneometry, there was no difference between the groups with and without itch with regard to the epidermal hydration values (Table 3).

However, there were significant correlations between itch intensity assessed by 4IIQ and 


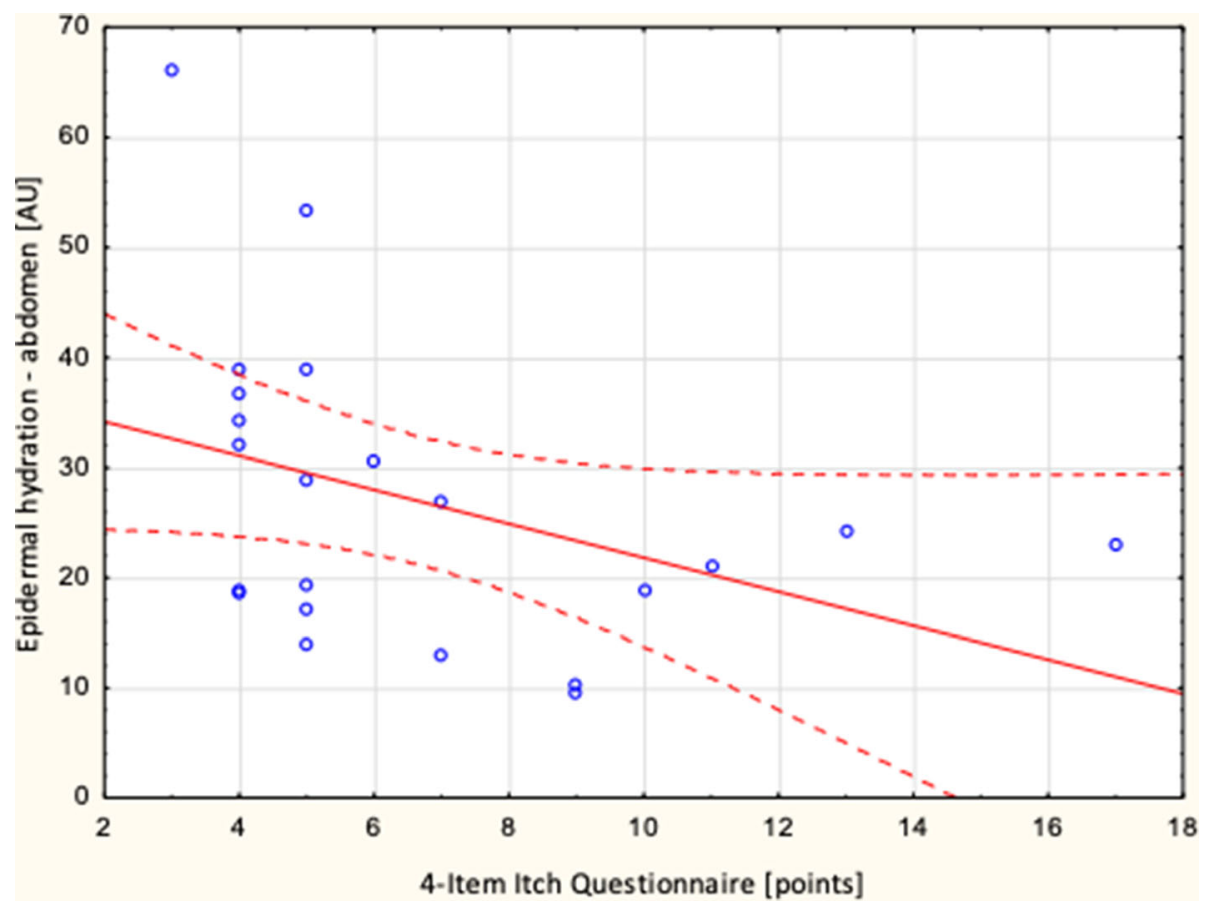

Fig. 2 Correlation between itch intensity measured with the 4-Item Itch Questionnaire and epidermal hydration on the abdomen $(R=-0,5 ; p=0.032)$

Table 4 Correlations between itch intensity and epidermal hydration

\begin{tabular}{lll}
\hline Epidermal hydration $(\mathbf{A U})$, mean $\mathbf{\pm}$ SD & NRS during the last 3 days & 4-Item Itch Questionnaire \\
\hline Forearm & NS & NS \\
Lower leg & NS & NS \\
Abdomen & NS & $R=-0.5$ \\
& & $(p=0.032)$ \\
Chest & NS & NS \\
\hline
\end{tabular}

$S D$ standard deviation, $N S$ not significant, $N R S$ numerical rating scale

epidermal hydration on the abdomen $(R=-0.5 ; p=0.032)$ (Fig. 2$)$. There were no relationships between itch severity evaluated with NRS and corneometric values (Table 4). Additionally, there were no significant correlations between itch intensity measured with the NRS and 4IIQ and skin xerosis, examined clinically (detailed data not shown).

\section{Itch and Quality of Life}

The mean CDLQI score in the itchy group was $4.0 \pm 4.7$ points (median 2.5, range 1-16 points), indicating small impairment of quality of life [26]. The intensity of itch (both NRS last 3 days and NRS last $24 \mathrm{~h}$ ) correlated positively with life quality impairment $(R=0.7 ; p=0.015$ and $R=0.8, p=0.002$, respectively). Additionally, the abdominal epidermal hydration 
correlated negatively with CDLQI $(R=-0.4$; $p<0.045)$.

\section{DISCUSSION}

To the best our knowledge, this is the first prospective study, investigating specifically the prevalence of itch among pediatric patients with T1D, in whom we obtained detailed characteristics and applied a comprehensive, validated methodology to characterize itch. We showed that itch occurred in more than $20 \%$ of children with T1D and those subjects who reported itch had more severe dry skin. These findings are in consistence with our previous study, where about $20 \%$ of children on dialysis treatment were suffering from uremic itch [18]. It was also clearly documented that diabetic itch markedly contributed to the impaired quality of life.

There are not many studies concerning cutaneous manifestations, including itch and dry skin, in children and adolescents with T1D. In 2007 Pavlovic et al. [27] studied the youngest population, comparable to ours. In the crosssectional study, they examined 212 patients with T1D aged 2-22 years (mean age $12.5 \pm 3.7$ years) and compared the results with 196 healthy children and adolescents. The most common skin manifestation was xerosis, found in $22 \%$ of type 1 diabetic patients. In control subjects, dry skin was demonstrated only in 3\% of the children and adolescents, the difference was highly significant. However, Pavlovic [27] did not exclude from their study group patients with other causes of xerosis, such as atopic dermatitis, etc. No patient with itch was reported. Romano et al. [28] in 1997 studied heterogeneous population of 477 patients with DM, of which 64 patients had T1D. Patients with T1D were mostly adolescents and young adults with mean age $22 \pm 8$ years, and mean diabetes duration of $10 \pm 4$ years. The studied population was older and with longer mean diabetes duration than our group. Skin xerosis was reported in 4 patients with T1D (6\%), and itch in 1 patient (2\%). Yosipovitch et al. [29] in 1998 performed a cross-sectional study with $238 \mathrm{~T} 1 \mathrm{D}$ patients aged $12-44$ years with a mean age of
$23.5 \pm 7.6$ years, and mean diabetes course of $13 \pm 2.5$ years (range: $5-37$ years). Only patients with disease onset at $<30$ years of age and with diabetes duration $>5$ years were qualified to the study. Skin xerosis was present in $48 \%$ of patients and only $0.4 \%$ of patients reported itching sensations. Khurdish et al. [30] studied older (above 15 years of age), mixed population of 350 diabetic patients, including 30 patients with T1D. Itch was not observed in the population of patients with T1D. In the study performed by Farshchian et al. [31] itch was reported by $17.4 \%$ of patients with T1D and this was no significant difference in comparison to their population of patients with type $2 \mathrm{DM}$ (27\% had itch).

Summarizing, taking into account available epidemiological data concerning itch in T1D, one may draw a conclusion that the studies on itch in T1D, employing currently accepted methodology, are practically missing. Studies on itch prevalence, based on all clinical cutaneous manifestations analyzed in T1D patients, have given conflicting results and are difficult to be compared with each other due to non-homogenous methodology. Most studies are based on the point prevalence of itch with no detailed data. It seems that $0 \%$ to $17.4 \%$ of patients with T1D may suffer from itch. Our study confirms this as itch during the course of DM was present in $22 \%$ of pediatric patients, while itch during the last three days was noted in $12 \%$ of studied subjects.

Pathogenesis of itch in DM is not fully understood and various factors have been suggested as contributing to the development of this symptom. Currently, it is believed that skin xerosis and diabetic polyneuropathy are the main factors influencing the occurrence and severity of itch in DM patients. In our cohort of patients, xerosis was more common in children with itch during the course of DM compared with those without itch. Moreover, epidermal hydration on the lower leg and abdomen correlated negatively the itch intensity. It is known that itching may occur in clinically inconspicuous dry skin [12, 32]. Seité et al. [33] assessed 40 diabetic patients, among them 32 (80\%) were diagnosed with $\mathrm{T} 1 \mathrm{D}$, with regard to stratum corneum (SC) hydration, skin barrier 
dysfunction (Trans Epidermal Water LossTEWL) and itching. The authors showed that emollient application induced a significant increase in skin hydration associated with a remarkable reduction in TEWL. This resulted in significant reduction of itch intensity. Sakai et al. $[34,35]$ proposed a thesis that patients with DM tend to develop a reduced hydration state of the SC together with decreased sebaceous gland activity. Unfortunately, data about the type of diabetes among their subjects, are missing. On the other hand, Seirafi et al. [36] provided a case-control study with 49 Japanese patients, among them 11 had T1D (22.5\%). They demonstrated no significant difference in SC hydration and TEWL in DM patients compared with age- and gender-matched healthy people. Additionally, it was pointed out that patients with DM had a lower acoustic wave propagation speed (related to skin elasticity). As a result of long-lasting DM patients may develop a cutaneous neuropathy with subsequent neuropathic itch. In the current study population, no diabetic polyneuropathy was found, probably because of the short course of diabetes ranging from 0 to 13 years with a mean duration of $4.6 \pm 3.6$ years. The American Diabetes Association recommends screening for diabetic neuropathy five years after diagnosis for someone with type 1 diabetes [25]. Therefore, we suggest that cutaneous neuropathy most probably does not play an important role in the pathogenesis of itch in T1D pediatric population.

What is interesting, no correlation was found between parameters associated with glycemic control-FPG and HbA1c and the presence and severity of itch, skin dryness and quality of life among our subjects. Only a few studies focused on the itch and a parameter of glycemic control and all of them were performed on adult population with diabetes type 2. Ko et al. [32] claimed that patients with a higher postprandial glucose level had a higher probability of having generalized itch $(p=0.02)$. Moreover, in newly diagnosed and untreated patients with type 2 DM Hillson et al. [37] found out the correlation between the FPG and generalized itch. The mean FPG level in itching subjects was $239 \pm 68 \mathrm{mg} / \mathrm{dl}$, significantly higher comparing to non-itching population-200 $\pm 74 \mathrm{mg} / \mathrm{dl} \quad(p<0.01)$. The mean FPG levels in our cohort of itchy subjects were $168.6 \pm 72.2 \mathrm{mg} / \mathrm{dl}$, which represents much lower values than in the above-mentioned study. Nearly $1 / 4$ th of patients with itch during the course of diabetes (22.7\%) considered diabetic diet (recommendation to consume products with a low glycemic index as well as carbohydrate counting in order to optimize prandial insulin dose) as itch alleviating, which, we can only speculate, may be consistent with the data presented by Hillson et al. [37].

In both above-mentioned studies, no relationship between HbA1c levels and itch has been found [32, 38].

In our group of pediatric patients with DM itch correlated with impairment of quality of life. This is in agreement with other studies on both cutaneous and systemic itch and quality of life assessment [16-18, 39-42]. It is generally accepted that chronic itch is the devastating symptom in the majority of itch patients.

This study has several limitations. Firstly, this was a single-centre study and the number of subjects with itch was relatively small, therefore, this study should be considered of an exploratory nature. The findings regarding the itch characteristics in pediatric population should be treated with caution. In addition, the descriptive nature of the study has to be taken into account. Secondly, concerning the neurological background of the itch, we did not consider the warmth detection thresholds. However, several other assessments were undertaken. Thirdly, the period of the study was relatively long starting in April and ending in December. Despite our efforts, additional factors such as change in the weather and connected to this, change in the patient's habits (different clothes, different sports) could affect the final results. Last but by no means least quality of life of our patients was measured with CLDQI. To the best of our knowledge there is no itch-specific instrument to evaluate influence of itch on quality of life in pediatric population, however the above-mentioned questionnaire was used to correlate the presence and intensity of itch with quality of life assessment in itchy adults [16, 17, 39-42]. 


\section{CONCLUSIONS}

In conclusion, our prospective study on children with T1D found itch as a moderately frequent symptom. We suggest that dryness of the skin may play a role in the pathogenesis of itch in this population. However, further multicenter studies, including a reasonable number of children with T1D, are necessary to confirm our findings.

\section{ACKNOWLEDGEMENTS}

We thank the participants of the study.

Funding. The publication was prepared under the project financed from the funds granted by the Polish Ministry of Science and Higher Education in the "Regional Initiative of Excellence" programme for the years 2019-2022, project no. 016/RID/2018/19. No Rapid Service Fee was received by the journal for the publication of this article.

Authorship. All named authors meet the International Committee of Medical Journal Editors (ICMJE) criteria for authorship for this article, take responsibility for the integrity of the work as a whole, and have given their approval for this version to be published.

Disclosures. Aleksandra A. Stefaniak, Agnieszka Zubkiewicz-Kucharska, Łukasz Matusiak and Anna Noczyńska have nothing to disclose. Jacek C. Szepietowski is a member of the journal's Editorial Board.

Compliance with Ethics Guidelines. The project was approved by the local ethics committee (ST.C260.18.019). The study procedures were carried out in agreement with the Helsinki Declaration of 1964 and its later amendments and good clinical practice guidelines. Written informed consent to participate was obtained from all children and their carers before enrollment; they were also informed of their right to leave the study at any time.
Data Availability. The datasets generated and analyzed in the current study are available from the corresponding author on reasonable request.

Open Access. This article is licensed under a Creative Commons Attribution-NonCommercial 4.0 International License, which permits any non-commercial use, sharing, adaptation, distribution and reproduction in any medium or format, as long as you give appropriate credit to the original author(s) and the source, provide a link to the Creative Commons licence, and indicate if changes were made. The images or other third party material in this article are included in the article's Creative Commons licence, unless indicated otherwise in a credit line to the material. If material is not included in the article's Creative Commons licence and your intended use is not permitted by statutory regulation or exceeds the permitted use, you will need to obtain permission directly from the copyright holder. To view a copy of this licence, visit http://creativecommons.org/licenses/by$\mathrm{nc} / 4.0 /$.

\section{REFERENCES}

1. Cho NH, Shaw JE, Karuranga S, et al. IDF diabetes atlas: global estimates of diabetes prevalence for 2017 and projections for 2045. Diabetes Res Clin Pract. 2018;138:271-81.

2. Pettitt DJ, Talton J, Dabelea D, et al. Prevalence of diabetes in US youth in 2009: the SEARCH for diabetes in youth study. Diabetes Care. 2014;37:402-8.

3. Williams G, Pickup J. Handbook of diabetes 2004.

4. Variation and trends in incidence of childhood diabetes in Europe. EURODIAB ACE Study Group. Lancet (London, England) 2000;355:873-6.

5. Ständer S, Streit M, Darsow U, et al. Diagnostic and therapeutic procedures in chronic pruritus. J Dtsch Dermatol Ges. 2006;4:350-70.

6. Steinhoff M, Bienenstock J, Schmelz M, Maurer M, Wei E, Bíró T. Neurophysiological, neuroimmunological, and neuroendocrine basis of pruritus. J Invest Dermatol. 2006;126:1705-18. 
7. Weisshaar E, Szepietowski J, Darsow U, et al. European guideline on chronic pruritus. Acta Derm Venereol. 2012;92:563-81.

8. Szepietowski JC, Reich A. [Itch. Pathomechanism, clinic, treatment]. Poznań: Termedia; 2010.

9. Alizadeh N, Mirpour SH, Golmohamadi R, et al. Chronic generalized pruritus without primary skin lesions: a longitudinal prospective observational study. Int J Dermatol. 2019;58:273-8.

10. Steinhoff M, Schmelz M, Szabó IL, Oaklander AL. Clinical presentation, management, and pathophysiology of neuropathic itch. Lancet Neurol. 2018;17:709-20.

11. Tseng H-W, Ger L-P, Liang C-K, Liou H-H, Lam H-C. High prevalence of cutaneous manifestations in the elderly with diabetes mellitus: an institution-based cross-sectional study in Taiwan. J Eur Acad Dermatol Venereol. 2015;29:1631-5.

12. Yamaoka H, Sasaki H, Yamasaki H, et al. Truncal pruritus of unknown origin may be a symptom of diabetic polyneuropathy. Diabetes Care. 2010;33: $150-5$.

13. Stefaniak A, Chlebicka I, Szepietowski J. Itch in diabetes: a common underestimated problem. Adv Dermatology Allergol 2019;36.

14. Association AD. 2. Classification and Diagnosis of Diabetes: Standards of Medical Care in Diabetes2020. Diabetes Care 2020;43:S14-31.

15. Reich A, Chatzigeorkidis E, Zeidler C, et al. Tailoring the cut-off values of the visual analogue scale and numeric rating scale in itch assessment. Acta Derm Venereol. 2017;97:759-60.

16. Chrostowska-Plak D, Reich A, Szepietowski JC. Relationship between itch and psychological status of patients with atopic dermatitis. J Eur Acad Dermatol Venereol. 2013;27:e239-e242242.

17. Suseł J, Batycka-Baran A, Reich A, Szepietowski JC. Uraemic pruritus markedly affects the quality of life and depressive symptoms in haemodialysis patients with end-stage renal disease. Acta Derm Venereol. 2014;94:276-81.

18. Wojtowicz-Prus E, Kiliś-Pstrusińska K, et al. Chronic kidney disease-associated pruritus in children. Acta Derm Venereol. 2016;96:938-42.

19. Reich A, Mędrek K, Szepietowski J. Four-item itch questionnaire-validation of questionnaire. Przegl Dermatol. 2012;99:600-4.

20. Geel MJ, Maatkamp M, Oostveen AM, et al. Comparison of the dermatology life quality index and the children's dermatology life quality index in assessment of quality of life in patients with psoriasis aged 16-17 years. Br J Dermatol. 2016;174: 152-7.

21. Olsen JR, Gallacher J, Finlay AY, Piguet V, Francis NA. Quality of life impact of childhood skin conditions measured using the Children's Dermatology Life Quality Index (CDLQI): a meta-analysis. Br J Dermatol. 2016;174:853-61.

22. Salek MS, Jung S, Brincat-Ruffini LA, et al. Clinical experience and psychometric properties of the Children's Dermatology Life Quality Index (CDLQI), 1995-2012. Br J Dermatol. 2013;169: 734-59.

23. Eberlein-Ko B, Nig È, Scha È Fer T, et al. Skin Surface $\mathrm{pH}$, stratum corneum hydration, trans-epidermal water loss and skin roughness related to atopic eczema and skin dryness in a population of primary school children. Acta Derm Venereol 2000;80(3): 188-91.

24. Cook TH, Craft T. Topographics of dry skin, nondry skin, and cosmetically treated dry skin as quantifed by skin profilometry. J Soc Cosmet Chem 1985:143-52.

25. Association AD. 11. Microvascular Complications and Foot Care: Standards of Medical Care in Diabetes-2020. Diabetes Care 2020;43:S135-51.

26. Waters A, Sandhu D, Beattie P, Ezughah FL-JS. Severity stratification of Children's Dermatology Life Quality Index (CDLQI) scores. Br J Dermatol 2010:121.

27. Pavlovi MD, Milenkovi T, Dini M, et al. The prevalence of cutaneous manifestations in young patients with type 1 diabetes. Diabetes Care. 2007;30(8):1964-7.

28. Romano G, Moretti G, Di Benedetto A, et al. Skin lesions in diabetes mellitus: prevalence and clinical correlations. Diabetes Res Clin Pract. 1998;39: $101-6$.

29. Yosipovitch G, Hodak E, Vardi P, et al. The prevalence of cutaneous manifestations in IDDM patients and their association with diabetes risk factors and microvascular complications. Diabetes Care. 1998;21:506-9.

30. Ahmed K, Muhammad Z, Qayum I. Prevalence of cutaneous manifestations of diabetes mellitus. J Ayub Med Coll Abbottabad;21:76-9.

31. Farshchian M, Farshchian M, Fereydoonnejad M, Yazdanfar A, Kimyai-Asadi A. Cutaneous manifestations of diabetes mellitus: a case series. Cutis. 2010;86:31-5. 
32. Ko M-J, Chiu H-C, Jee S-H, Hu F-C, Tseng C-H. Postprandial blood glucose is associated with generalized pruritus in patients with type 2 diabetes. Eur J Dermatol 23:688-93.

33. Seité S, Khemis A, Rougier A, Ortonne J. Importance of treatment of skin xerosis in diabetes. J Eur Acad Dermatol Venereol. 2011;25:607-9.

34. Sakai S, Kikuchi K, Satoh J, Tagami H, Inoue S. Functional properties of the stratum corneum in patients with diabetes mellitus: similarities to senile xerosis. Br J Dermatol. 2005;153:319-23.

35. Sakai S, Endo Y, Ozawa N, et al. Characteristics of the epidermis and stratum corneum of hairless mice with experimentally induced diabetes mellitus. J Invest Dermatol. 2003;120:79-85.

36. Seirafi H, Farsinejad K, Firooz A, et al. Biophysical characteristics of skin in diabetes: a controlled study. J Eur Acad Dermatol Venereol. 2009;23: 146-9.

37. Hillson RM, Hockaday TD, Newton DJ, Pim B. Delayed diagnosis of non-insulin-dependent diabetes is associated with greater metabolic and clinical abnormality. Diabet Med. 1985;2:383-6.

38. Neilly JB, Martin A, Simpson N, MacCuish AC. Pruritus in diabetes mellitus: investigation of prevalence and correlation with diabetes control. Diabetes Care;9:273-5.

39. Reich A, Hrehorow E, Szepietowski J. Pruritus is an important factor negatively influencing the wellbeing of psoriatic patients. Acta Derm Venereol. 2010;90:257-63.

40. Reszke R, Białynicki-Birula R, Szepietowski JC. Itch in psoriasis: a new look at well-known subject. Acta Derm Venereol. 2019;99:429-34.

41. Kaaz K, Szepietowski JC, Matusiak Ł. Influence of itch and pain on sleep quality in atopic dermatitis and psoriasis. Acta Derm Venereol. 2019;99:175-80.

42. Matusiak $Ł$, Szczęch J, Kaaz K, Lelonek E, Szepietowski JC. Clinical characteristics of pruritus and pain in patients with hidradenitis suppurativa. Acta Derm Venereol. 2018;98:191-4. 